\title{
possibilities for migration anthropology
}

\author{
COLLEEN G. O'NEAL_University of Michigan
}

\author{
Changing Identities: Vietnamese Americans \\ 1975-1995. JAMES M. FREEMAN. Needham \\ Heights, MA: Allyn and Bacon, 1995. ix + 141 \\ pp., references.
}

From the Workers' State to the Golden State: Jews from the Former Soviet Union in California. STEVEN J. GOLD. Needham Heights, MA: Allyn and Bacon, 1995. xix + 138 pp., references.

New Pioneers in the Heartland: Hmong Life in Wisconsin. JO ANN KOLTYK. Needham Heights, MA: Allyn and Bacon, 1998. xiv + 146 pp., notes, photographs, references.

From the Ganges to the Hudson: Indian Immigrants in New York City. JOHANNA LESSINGER. Needham Heights, MA: Allyn and Bacon. 1995. xvi + 166 pp., references.

Salvadorans in Suburbia: Symbiosis and Conflict. SARAH J. MAHLER. Needham Heights, MA: Allyn and Bacon, 1995. xxix + 137 pp., notes, references.

An Invisible Minority: Brazilians in New York City. MAXINE L. MARGOLIS. Needham Heights, MA: Allyn and Bacon, 1998. xiii + 140 pp., notes, photographs, postscript, references.

Changes and Conflicts: Korean Immigrant Families in New York. PYONG GAP MIN. Needham Heights, MA: Allyn and Bacon, 1998. X + 133 pp., photographs, references.

A Visa for a Dream: Dominicans in the United States. PATRICIA R. PESSAR. Needham Heights, MA: Allyn and Bacon, 1995. xvi + 98 pp., notes, references.

Pride against Prejudice: Haitians in the United States. ALEX STEPICK. Needham Heights, MA: Allyn and Bacon, 1998. X + 134 pp., note, references.

Ethnicity and Entrepreneurship: The New Chinese Immigrants in the San Francisco Bay Area. BERNARD WONG. Needham Heights,
MA: Allyn and Bacon, 1998. viii + 120 pp., references.

This article reviews the New Immigration Series, a collection of ten slender ethnographically styled texts published in 1995 and 1998 by Allyn and Bacon and edited by Nancy Foner. In this series, national population statistics, local population profiles, and selected excerpts from case studies are framed within migration history, transnational residence patterns, and the political economy of United States immigration. The populations studied include Brazilians, Chinese, Dominicans, Haitians, Hmong, Indians, Koreans, Russians, Salvadorans, and Vietnamese who have, in recent decades, entered cities, towns, and suburban areas in the United States as immigrants, refugees, sojourners, and undocumented aliens. The texts are pitched to undergraduate, policy making, and advocacy oriented readers, although some area specialists may find them useful; they might also provide core reading for a graduate course if supplemented with material to challenge their capitulation to the concepts of an earlier moment.

While anthropologists have begun to develop alternative concepts for the analysis of global migration and the subsequent reconstitution of identity and culture, the New Immigration Series is out of step with such trends. In the main, ethnographers in this series have passed up the opportunity to apply such concepts as diaspora, internationalism, public culture, and civil society to the analysis of local and global historical encounters. Their use of the concept of transnationalism to explore new social forms created through binational residence constitutes the major exception. The series falls somewhere between an older tradition of demographically oriented migration studies (where the population is taken as the primary unit of analysis), and an emergent migration anthropology (where alternative analytical resources and an appreciation for how cultural reinvention is negotiated are brought more actively into play). The weakness of this series rests in the application of a limited conceptual apparatus to the ethnographic evidence, as well as in an anachronistic conception of culture as 
shared tradition. Its strength lies in its sociology and commendable, though limited and uneven effort, to expand the range of migration studies with political-economic and transnational analysis. Notwithstanding its failure of ethnographic imagination, the series marks recent trends in United States immigration and, for this reason, merits our attention.

The New Immigration Series attests to what demographic and sociological profiles of discrete populations offer the cultural, historical, and political economic analysis of global migration. That these ethnographies identify significant features of family and community life, gender and generational dynamics, labor patterns, and discriminatory practices raises an important question for the anthropology of global migration: How can sociology and demography be put to use as a resource within the anthropological text, rather than as an end in itself?

This review suggests a number of ways the traditional approach to the study of global migration might be expanded to accommodate alternative conceptual categories, a more encompassing historiography, and a more rigorous analysis of culture.

\section{out of migration studies}

The ethnographies are organized by chapters on migration history, resettlement, family, work and economy, community, identity, and culture. The analysis of family, work, and economy yields especially well on recent trends in U.S. immigration. The family is depicted as a demographic and gendered unit of analysis. As a demographic unit, the family incorporates fictive and adopted kin as well as nonrelatives as they extend over international borders along transnational migration circuits. Through this same unit, class and generational issues, including occupational and educational success, intergenerational tension, intraethnic exploitation, and ethnic solidarity are found to turn on competency in English. As a gendered unit of analysis, the family is represented as a site of conflict between spouses (Margolis, Min, Mahler, Pessar, Freeman, Lessinger). Increased participation of immigrant women in the work force and their increased contribution to household income has provided them with more autonomy outside and more power inside the household than they enjoyed before migration. Only Lessinger observes that women's enhanced earning power can result in a concomitant increase in domestic violence. Greater participation of women in the work force also requires modification of child-rearing strategies, including an increase in latchkey children in some populations; revaluation of daughters over sons in others; and, for many, patterns of elderly immigration for child care.

The categories of work and economy yield similarly well on recent trends as they coalesce around a set of relationships that go a long way to describe, if not explain, dominant patterns of immigrant labor. First, all immigrants with poor language skills are handicapped, albeit differently. Limited English need not be a problem if exogenous contacts occur within ethnic enclaves, or if fluency is irrelevant to securing work (especially work in restaurants, light manufacturing, housekeeping, child care, shoe shining, exotic dancing, street vending, landscaping, grocery work, dry cleaning, and nail salons). Second, a flexible and overqualified work force is so valuable in the current economy that some employers routinely violate the 1986 Immigration Reform and Control Act by hiring undocumented aliens (Pessar, Margolis). Even so, racism against African Americans extends to Haitians of lower educational levels and results in higher rates of unemployment for this group (Stepick). Third, the glass ceiling stunts the careers of professionals, with some returning home for more lucrative positions that draw on their United States work experience and transnational expertise (Lessinger, Min, Wong).

From within discussions of work and economy, the authors bring sociological variation across immigrant communities to the fore, especially when this variation can be used to argue against erroneous, if widely held, stereotypes. For example, Wong and Min confirm that many Chinese and Korean immigrants live and work in strong and cohesive ethnic enclave economies, while others do not (Wong, Min). In contrast to those who argue that immigrants detract from the American economy, Stepick and Mahler assert that Haitian and Salvadoran immigrants contribute to the economy by working in undesirable and low-paying jobs in the service and light manufacturing sectors. While it may be common to assume that immigrants are less well educated than the native born, several authors counter that Russian Jews, Koreans, Indians, and Vietnamese bring higher levels of educational achievement to bear on the fields of engineering, business, and medicine than do native-bom Americans (Gold, Min, Lessinger, Freeman).

However skilled and productive many new immigrants may be, most face resistance to linguistic diversity, whether as school children lagging behind in monolingual classrooms, culture brokers inverting generational hierarchies when translating for monolingual parents, or skilled workers limited by poor English (Min, Cold, Pessar, Freeman). Newly arrived immigrants must further contend with discriminatory real estate practices that present a formidable barrier to their obtaining housing. A successful strategy for achieving financial stability is to share the high cost of housing with several working adults, but the resultant overcrowding prompts real estate agents to refuse services to immigrants they perceive as threatening the quality of the housing stock (Mahler, Pessar, Margolis, Koltyk). Visiting workers and undocumented migrants must cope with the compound effects of nativist discrimination and intraethnic marginalization. Before migration, for example, strategies of visa procurement are often closely held knowledge, of which the lower classes are systematically deprived (Margolis, Wong). Long after migration the play of power and knowledge remains salient lawyers who take advantage of immigrants' poor English to exploit green card applicants, through employers and husbands who confiscate green cards, and other family members who charge the newly arrived exorbitant rents and fees (Margolis, Lessinger, Pessar). Undocumented immigrants are especially vulnerable to the profit-making schemes of remittance couriers, 
document counterfeiters, and informers within their own communities (Mahler).

As the foregoing discussion suggests, the categories of migration studies have been used to good effect to generate well-informed and loosely comparable sketches of discrete urban populations. They enable the authors to describe general trends in United States immigration and to highlight unique characteristics of local populations. Yet these same categories overdetermine the analysis to such an extent that the books read more as expanded commentaries on census reports than as ethnographies oriented to a set of questions driven by both evidence and disciplinary concerns.

These texts are limited further by their interpretation of culture.

\section{beyond culture as tradition}

The series relies heavily on a concept of culture as tradition. This interpretation lends itself well to analysis of the shared practices of discrete groups. It is less effective for analyzing how immigrants bring historical encounters with power and difference under symbolic and social control. The reader must therefore hunt through these texts for instances of immigrants using culture to contain the excesses of power and difference encountered in their migration experiences. For example, Hmong refugees when awaiting resettlement in Thai camps imagined America as a monster with teeth like long bananas. Now in the United States, many still believe Jeffrey Dahmer is this monster's incarnation (Koltyk). Russian Jewish emigrés seek through critical discourse to contain what they perceive to be the excesses of American society, its violence, shallowness, and commercialism (Gold). Koreans and Chinese attempt to preserve the integrity of their cultural practices by voluntarily self-segregating, Koreans and Indians by sending their children home for culture training, and others by discouraging marriage across ethnic and national boundaries (Wong, Min, Lessinger). At work, many immigrants achieve symbolic if not effective control in difficult situations through job turnover and resistance tactics. Female domestic and child care workers quit when pushed too far; and others employed in light manufacturing and service industries use slowness, gossiping, and wasting of materials (Mahler, Wong) to redress workplace inequities.

While cultural reinvention is another new area of inquiry in the discipline at large-especially how this collective process is negotiated and given political valence-these authors have simply catalogued the range of new cultural forms (such as soap operas, documentaries, sermons, and ballads) and documented the public sites in which they occur (including ethnic enclaves, credit associations, churches, and street festivals-Stepick, Koltyk, Mahler, Pessar, Freeman, Lessinger, Wong, and Min). An extended analysis of one or a few of these forms may have given undergraduates a better sense for how culture reinvention works. Among the authors, Lessinger goes farthest to note that ethnic organizations can be highly contested domains of sociability as well as venues for activism, especially when family and gender are at issue. More extreme forms of conflict, including political factionalism, gang violence, drug trading, domestic violence, and child abuse, while everyday realities in some immigrant communities, remain undeveloped in Lessinger's account and in the series in general. Paradoxically, this omission only reinscribes the model minority myth these authors have dedicated so many pages of text to dispel. It is an empirical question whether the near absence of conflict and violence can better be attributed to a conception of culture as shared, a patterned and unacknowledged tension between advocacy and analysis, a failure of the discipline to offer sufficient guidance in the analysis of violence, an attempt to soften conflict for an undergraduate audience, or to other factors altogether. However this shortcoming is to be explained, without conflict culture resembles age-old tradition to which all members of the group are assumed to conform. Min and Wong's argument that Confucian principles of filial piety, patriarchy, and educational achievement inform Korean and Chinese immigrant family structure and identity formation, just as they did in Korea and China, is an extreme example of this view of culture as tradition.

The authors consider identity far more extensively than cultural mediation and reinvention, and in this respect contribute more successfully to disciplinary conversations about culture. In Alan Stepick's study, Haitians in Miami are found to cycle through multiple identities in response to both racial discrimination in the United States and to an active interchange with the homeland. Stepick links the expression of these relational identities among Haitian teenagers to their chances of success in the school system. Jo Ann Koltyk reports that Hmong identity is clan rather than ethnic based; Freeman notes that racial identity politics are salient for Vietnamese immigrants after migration; and Gold finds that identity politics were more crucial for Russian lews before migration, when an appeal to biological difference secured their survival under a repressive political regime. Simultaneous participation in United States and homeland social, economic, and political life also makes new forms of identification possible, with Brazilians and Indians experiencing their transnational identification differently. Middle-class Brazilians identify as "economic prospectors" (p. 9) and elite Indians as members of a panIndian global community (Margolis, Lessinger).

Had the authors considered the investments immigrants make in maintaining their new identities and the lengths they go to preserve them, they could have better explained how power is exercised in identity formation at both ends of transnational migration circuits.

\section{toward a hybrid subdiscipline}

Among the volumes in this series, Sarah Mahler's trenchant critique of the politics of Salvadoran migration points most clearly to the limits of the categorical approach by framing Salvadoran migration in a distinctly anthropological fashion. Her historical ethnography neither undermines the clarity and straightforwardness of an introductory text nor does it capitulate to or abandon altogether the categories of migration studies. She does, however, stray from 
the series' formulaic outline of family, work, and economy to represent Salvadoran migration as a political, economic, and interpretive phenomenon. Through her ethnography of fear and resigned oppression on Long Island, Mahler draws on theory to unsettle received notions of what suburbia might mean in the history of American immigration and in the everyday lives of Salvadoran migrants. In this way, she draws migration studies more directly into the mainstream of anthropological practice. Mahler's ethnography is an outstanding example of how the categories of migration studies can be transcended through the application of alternative analytic resources suggested by the particularities of the field situation and the population under study.

As have the Salvadorans studied by Mahler, so too have other immigrant groups been subject to changing United States foreign and immigration policies, patterns of international labor migration, repressive national politics, and physical persecution (Freeman, Pessar, Stepick, Mahler, Gold, Koltyk). The relation between previous United States military and political intervention and domestic demands for labor in the service, light manufacturing, and professional sectors emerges with clarity and force as one reads across the series, making it difficult to imagine how one would reach the same conclusions if teaching from selected volumes. Analysis of the new immigration is particularly incisive when located in national (Stepick, Mahler, Freeman) and migration histories (Min, Margolis, Wong, Gold, Pessar, Lessinger), in the relation of United States immigration and refugee policy to Cold War politics (Gold, Wong), and in United States military (Freeman, Stepick) and counterinsurgent interventions (Mahler, Koltyk). Once again, violence is inadequately addressed (Stepick, Min, Wong, Koltyk, Gold, Mahler, Freeman).

The ethnographers of the New Immigration Series also draw migration studies into anthropology through a transnational perspective on the cultivation of ties to countries of origin through the flow of people, gifts, goods, ideas, and money. They catalogue immigrant-produced media and document the emergence of new organizations that allow for simultaneous participation across national boundaries (Pessar, Freeman). They examine the social organization of in-, out- and return migration with attention to economics, family structure, and gender. Immigrant men, for example, tend to return home more often than immigrant women and are sometimes specially equipped by their United States experience to run for political office (Min, Wong, Lessinger, Margolis). The authors also present evidence for remittances running as high as \$4-6 billion per year among the groups studied (Margolis, Stepick, Min, Mahler, Pessar, Freeman). Not surprisingly, sending countries attempt to secure this income source by influencing United States immigration policy and by cultivating home country identification through cultural exchange programs and dual citizenship. However, the question of how transnational residence alters the meaning and practice of citizenship, interpretation of the social contract, and the contours of civil society itself receives scant mention in this series, and rates of citizenship acquisition are poorly reported.
While the New Immigration Series excels in its treatment of the geopolitics of migration and falls in step with recent trends in transnational analysis, it does so mainly in the aggregate. Provided with only a two-page preface, the reader must work hard to identify the interventions this series proposes, harder still to explain its orientation to these populations, given recent developments in the anthropology of global processes. The series and the individual volumes would have benefited from the inclusion of an introductory essay to lay out the logical structure of the series as a whole, discuss the authors' significant findings, and underscore their individual and collective contributions to anthropology. As it stands, the reader is ill equipped to assess why some populations were selected for analysis, and others-Mexican, Irish, and Filipino, for example-were not. The reader must likewise speculate why the series favors New York and San Francisco over other large cities where immigrants have settled (such as Los Angeles, Miami, Anaheim, Chicago, Washington, D.C., and Houston) and why immigrants in very large cities were selected over immigrants in less populated areas, given that the latter constitute half of the United States immigrant population.

\section{into migration anthropology}

Too little has likewise been written about the venues (both public and private) in which these new immigrants and the rest of the United States population meet and realize their differences, similarities, and mutual interdependence. Through high participation in the service, domestic, and professional sectors, immigrants are now moving directly into suburbia and achieving greater visibility (Mahler, Koltyk, Gold). Yet the authors seem to suggest that nativism and discrimination are the only possible forms of social interaction between the native population and the twenty million foreign born in the United States. The New Immigrant Series suggests that long hours at work, language, and cultural difference alone can account for the limited contact they document between foreign born and native born persons in the United States population. Is such interaction really so limited? If so, is the desire for limited interaction mutual?

Anthropologists have begun to study global migration through an array of conceptual categories that lends itself well to analysis of hybrid national cultures. The study of United States immigration is rendered compelling by this opportunity to write the native born into the picture.

At the very least, taking advantage of this opportunity will require enlarging the scope of migration history so that national histories might be extracted from and written back into the historical record through accounting for immigrants old and new, for the role of the state in their creation and management, and for the record of their participation in and exclusion from debates on the form and content of national culture.

In sum, the New Immigrant Series is an accessible collection of short, loosely comparable population portraits of ten immigrant communities that have formed in United States cities over the past 
three decades. In their most inspired moments, the authors move readers from the historical and political-economic field on which immigrants and refugees are produced to the microlandscapes of urban life in the United States and to a lesser extent in the immigrants' home countries. The careful reader is rewarded with a sharper sense for how United States political intervention, the production of im- migrant and refugee populations, and the cyclical demand for labor, both skilled and unskilled, are historically related. Yet the reader is also left wondering precisely how, and in what venues, cultural reinvention is negotiated and how, and in what forms, these new immigrants attribute meaning to the historical circumstances that produced them as immigrants in the first place. 